\title{
Betel chewing among bus drivers in Jaffna district
}

\author{
S Selvananthan 1 , S Sivaganesh'², S Vairavanathan ${ }^{1}$, R Surenthirakumaran ${ }^{3}$, S Balakumar ${ }^{2}$
}

\begin{abstract}
Objective To assess the prevalence, pattern and sociocultural factors associated with betel chewing among bus drivers in Jaffna district.
\end{abstract}

Methodology Cross-sectional study was conducted among 423 registered drivers using an interviewer administered questionnaire from March to April 2014.

Results All were males. Mean age of the respondents was 41.42 years $(S D= \pm 10.3$; range $20-65)$. The overall prevalence of betel chewing was $70.4 \%$. Of the total $9.4 \%$ had chewed betel in the past. Of the current users $61 \%$ had chewed betel for more than 5 years. Betel was chewed daily by $89.2 \%$. (of them $60.8 \%$ used $\leq 3$ times). Almost all current chewers used areca nut. Fifty five percent of the drivers said they used betel to improve concentration while driving. Seventy five percent of those who used betel in the past said that staining of teeth was the reason for stopping the habit. Private bus drivers were more likely to chew betel while driving than SLTB drivers $(p=0.002)$.

Conclusion The prevalence of betel chewing among bus drivers in Jaffna District was high. Majority had chewed betel for more than five years. Areca nut was a main ingredient of betel quid.

Ceylon Medical Journal 2018; 63: 68-71

DOI: http://doi.org/10.4038/cmj.v63i2.8686

\section{Introduction}

Betel and areca nut is chewed by approximately 600 million people worldwide [1]. Betel quid consist of betel leaf, areca nut which is the main psychoactive ingredient and slaked lime (calcium hydroxide). Areca nut is said to be the fourth most commonly used psychoactive substance in the world, after caffeine, nicotine and alcohol. Other ingredients and flavouring agents are added according to local preferences and practices [2].

Betel chewing is prevalent in India, Pakistan, Bangladesh, Sri Lanka, Malaysia, Myanmar, Indonesia, Singapore, Philippines, Papua New Guinea, Micronesia,
Fiji, Maldives and Carolene Santa Cruz Islands. Asian migrants introduced betel to the Middle East, some African and European countries and the United States of America. Betel chewing was prevalent in many parts of China up to about the 19th Century when the use of opium took its place [3].

Use of $8-10 \mathrm{~g} /$ day of areca nut may be lethal and will cause narcolepsy, sedation and death. Frequent use can stain teeth black and daily use is associated with increased risk of cancers of liver, mouth, stomach, prostate, cervix, lung, reduced sexual potency and dependence [4]. The adverse health effects associated with betel chewing (with areca nut) include oral and oropharyngeal cancer, oral premalignant lesions and some conditions such as oral leukoplakia, submucous fibrosis and dependence [10]. Betel chewing accounts for about $90 \%$ of oral cancer diagnosed in Sri Lanka. Areca nut is the main ingredient that causes oral cancers. Sri Lanka occupies fifth place in the prevalence of oral cancers [5].

The government spends about Rs. 1 million on the care of a cancer patient. About 600 million people, $20 \%$ of the world population chew betel. Nearly $53 \%$ of the rural community in Sri Lanka chew betel, specially estate workers, labourers, and drivers [5]. Betel chewing is thought to reduce hunger and relieve tiredness which perhaps is the reason why some manual workers chew betel while working [3].

A study conducted in Colombo and Polanaruwa Districts in 2006 reported a prevalence of betel chewing of $17.6 \%$ in the rural and $1.7 \%$ in the urban district. In the rural district prevalence was significantly associated with age $(p<0.001)$. In both districts prevalence was lowest among males between 18-24 years of age (2.7\%) and highest among those aged $>65$ years $(36 \%)$. In both urban and rural areas, prevalence was significantly associated with income $(p<0.05)$. Prevalence was highest among those with a monthly income $<$ Rs.5000. In rural areas $23.8 \%$ of those with an income $<$ Rs. 5000/month chewed betel while only $4.7 \%$ of those earning >Rs. 25000 a month chewed betel [7].

Bus drivers use psychoactive substances including alcohol (3\%), tobacco (53\%) and betel chewing (80\%).

${ }^{1}$ Faculty of Medicine, University of Jaffna, ${ }^{2}$ Regional Epidemiologist RDHS Office, Jaffna, ${ }^{3}$ Lecturer in Community Medicine, Consultant Community Physician, Department of Community Medicine, Faculty of Medicine, University of Jaffna, Sri Lanka.

Correspondence: SS, e-mail: <suganja.info@gmail.com>. Received 18 April 2018 and revised version accepted 19 April 2018.

This is an open-access article distributed under the terms of the Creative Commons Attribution License, which permits unrestricted use, distribution, and reproduction in any medium, provided the original author and source are credited. 
About $25 \%$ of bus drivers chew betel without adding lime or chewing tobacco [5]. A recent survey conducted by the National Cancer Control Programme in Sri Lanka has revealed that $80 \%$ of bus drivers and conductors are vulnerable to oral cancer. Excessive chewing of betel and smoking cigarettes by drivers and conductors throughout the journey and while waiting for their next turn have been identified as main reasons for this vulnerability [6].

A survey conducted by the Institute of Oral Health, Maharagama, on 103 bus drivers and conductors working in buses in the Maharagama and Dehiwala areas revealed that more than $80 \%$ chew betel to keep themselves awake and improve concentration [8]. A study carried out in Pakistan showed that knowledge regarding carcinogenicity of betel, areca nut and tobacco among users are poor. [9].

According to the Tobacco and Alcohol Act of 2006 it is an offence to drive under the influence of drugs and therefore bus drivers should not use chew betel [5]. But we observed that betel chewing was common among bus drivers in Jaffna. The objective of the study was to assess the prevalence, pattern and sociocultural factors associated with betel chewing among bus drivers in the Jaffna District.

\section{Methods}

\section{Design and setting}

We conducted a cross sectional analytical study from October 2013 to May 2014 among registered bus drivers of the Sri Lanka Transport Board (SLTB) and private bus services in the Jaffna District.

We recruited 423 (113 SLTB and 310 private bus drivers) out of 777 drivers (177 SLTB and 600 private bus drivers) by non-proportionate stratified sampling. Sample size was calculated using the standard formula with the following parameters: preliminary estimation of proportion- 50\%; alpha error- 0.05 and level of precision- $5 \%$. Data was collected using an interviewer-administered questionnaire.

Ethical clearance was obtained from the Ethics Review Committee of the Faculty of Medicine, University of Jaffna. Written informed consent was obtained from all participants.

Data was analyzed using SPSS 21. Descriptive statistics, chi-squared test and odds ratio were used to describe the results.

\section{Results}

There were 423 completed questionnaires. All were males. Of 423 respondents, $310(73.3 \%)$ were private bus drivers. Mean age of the respondents was 41.42 years
$( \pm \mathrm{SD}=10.3$; range 20-65). Majority of the respondents 226 $(53.4 \%)$ were aged between $20-40$ years and $21(5 \%)$ were aged more than 60 years (Table 1 ).

Table 1. Description of the sample

\begin{tabular}{ll}
\hline & Number $(\%)$ \\
\hline Age & \\
$20-40$ years & $226(53.4)$ \\
$41-60$ years & $176(41.6)$ \\
$>60$ years & $21(5.0)$ \\
\hline Employer & \\
SLTB & $113(26.7)$ \\
Private bus & $310(73.3)$ \\
\hline
\end{tabular}

\section{Prevalence of betel chewing}

Of the 423 drivers, 298 chewed betel quid. Current prevalence was $70.4 \%$ (95\% CI 66.4-74.7\%). Forty one $(9.7 \%)$ had chewed betel in the past. Eighty seven $(76.9 \%)$ SLTB drivers and $211(68.1 \%)$ private bus drivers chewed betel (chi sq 3.17, $p=0.08$ ).

\section{Pattern of betel chewing}

Among current users $183(61.4 \%)$ drivers had chewed betel for more than 5 years and 115 (38.6 had used for less than 5 years. Among current users $265(89.2 \%)$ chewed betel daily. Of the 265 daily users $161(60.8 \%)$ chewed betel $\leq 3$ times a day. One hundred and two $(38.5 \%)$ used 4-10 times a day. Only two $(0.7 \%)$ drivers reported using more than 10 times a day. Out of 298 users, $296(99.3 \%)$ used areca nut, $254(85.2 \%)$ used lime, and $179(60.1 \%)$ used tobacco with betel. Cinnamon and cloves were used by a few. None of them used drugs.

\section{Sociocultural factors}

Out of 339 users (past and present), 188 reported that the main reason for use was to help concentration while driving. The reasons for betel chewing are described in Table 2. One hundred and sixty one (38.1\%) thought it prevented them falling asleep while driving; $112(26.5 \%)$ thought it prevented bad breath; 91(21.5\%) thought it increased concentration. Hundred and twenty four (29.3\%) chewed betel while driving. Of 41 past chewers, $31(75.6 \%)$ stopped chewing because it stained their teeth. Private bus drivers $(n=86 ; 35.5 \%)$ were more likely than SLTB drivers $(n=16 ; 16.3 \%)$ to identify peer-pressure as the reason for betel chewing (Chi sq=12.3; $p<0.001$ ). Private bus drivers were also more likely to chew betel while driving $(\mathrm{n}=9968.2 \%)$ than SLTB drivers $(\mathrm{n}=25$; $44.6 \%$ ) (chi sq $9.5 ; p=0.002$ ). 
Table 2. Pattern of betel chewing

\begin{tabular}{|c|c|c|}
\hline & Number & $\%$ \\
\hline \multicolumn{3}{|l|}{ Time of use } \\
\hline While driving & 124 & 29.3 \\
\hline Only before driving & 12 & 2.8 \\
\hline After driving only & 12 & 2.8 \\
\hline Before or after driving & 78 & 18.4 \\
\hline At home after finishing work & 36 & 8.5 \\
\hline At night & 33 & 7.8 \\
\hline \multicolumn{3}{|l|}{ Reasons for use } \\
\hline Cultural & 53 & 15.5 \\
\hline Others in the family use & 102 & 29.9 \\
\hline Peer pressure & 102 & 29.9 \\
\hline Feelings of craving & 28 & 8.2 \\
\hline Helps concentration & 188 & 55.1 \\
\hline Because of depression or sadness & 62 & 18.2 \\
\hline To prevent bad breath & 123 & 36.1 \\
\hline To prevent hunger & 49 & 14.3 \\
\hline To refresh breath & 75 & 22.0 \\
\hline To look mature & 2 & 0.6 \\
\hline Because it is easily available & 16 & 4.7 \\
\hline \multicolumn{3}{|c|}{ Reasons for cessation of the habit } \\
\hline Offensive breath & 9 & 22 \\
\hline Staining of teeth & 31 & 75.6 \\
\hline Awareness of harmful effects & 23 & 56.1 \\
\hline Family members didn't approve & 12 & 29.2 \\
\hline Burned the mouth & 13 & 31.7 \\
\hline Other reasons & 1 & 2.4 \\
\hline
\end{tabular}

\section{Discussion}

Our study reports the prevalence of current betel chewing of 70.4\% among bus drivers in the Jaffna District and $9.4 \%$ were past users. Sixty one percent of current chewers had chewed betel for more than 5 years. Of the users $89.2 \%$ said they chewed betel daily. Almost all current users also used areca nut. Fifty five percent of the drivers said they chewed betel to improve concentration while driving. Of the past users $75 \%$ said that staining of teeth was the reason for stopping use.

A study done in Taiwan reported that betel chewers were mostly in their 30s and 40s, similar to findings from our study [11]. A study carried out in Bangladesh showed that overall, $33.2 \%$ of the study population chewed betel quid currently and an additional $1.7 \%$ had chewed betel in the past [12]. Prevalence of betel chewing was higher among our populations possibly because it consisted of bus drivers.
A study conducted in Karachi reports very high rates of daily use of betel and areca (74\% and 35\%) among primary school children, with frequency increasing from lower to higher grades [13]. Another study reported that the lowest mean frequency of use per day for any substance was 6.5 , which indicates the addictive potential of these substances [14].

A study conducted in Bangladesh reported that areca nut was the commonest added ingredient with $67 \%$ of both men and women adding this to the betel quid. Women were more likely to add tobacco [15]. We too found that areca nut was the commonest added ingredient.

\section{Acknowledgement}

The authors wish to acknowledge the participants and staff of the Department of Community and Family Medicine, University of Jaffna.

\section{Conflict of Interests}

Authors declare that there are no conflicts of interest.

\section{References}

1. Nelson BS, Heischober B. Betel nut: a common drug used by naturalized citizens from India, Far East Asia and the South Pacific Islands. Ann. Emerg. Med 1999; 34: 238-43.

2. Gupta PC, Ray CS. Epidemiology of betel quid usage. Ann Acad Med Singapore 2004; 33: 31-6.

3. Pethiyagoda ACB. A cardinal pleasure; Betel chewing. Saturday magazine 2002 http://www.island.lk/2002/03/16/ satmag04.html (accessed on Jan 17, 2014).

4. Sinead OC. Psychoactive substances. A Guide to ethnobotanical plants and herbs, synthetic chemicals, compounds and products 2010; 1.1:30.

5. Siriwardana K. $90 \%$ oral cancer caused by chewing betel. Ceylon Today 2012; 17: 2.

6. Irangika R. Eighty percent of bus crews cancer-prone. Daily News 2012; 16: 2.

7. De Silva VA, Hanwella DRC, Gunawardena N. Prevalence of betel chewing among males in Colombo and Polonnaruwa districts. Journal of the Ceylon College of Comminity Physicians 2009; 14: 20-23.

8. Chrishanthi C. Betel-chewing bus drivers on a dangerous high. 2016 http://www.sundaytimes.lk/150517/news/betelchewing-bus-drivers-on-a-dangerous-high-149168.html (accessed on Jan 17, 2014).

9. Khan MS, Bawany FI, Shah SR, Hussain M, Arshad MH, Nisar N. Comparison of knowledge, attitude and practices of betelnut users in two socio-economic areas of Karachi. J Pak Med Assoc 2013; 63: 1319-25.

10. Eric O, Demaine L, Saman W. Areca Nut Chewing Habit Among High School Children In Commonwealth Of Northern Mariana Islands. Bull World Health Organ 2005; 83: $656-60$. 
11. Wen CP, Tsai SP, Cheng YT, et al. Uncovering the relation between betel quid chewing and cigarette smoking in Taiwan. BMJ 2005; 14: 26-9.

12. Heck J E, Marcotte EL, Argos M, et al. Betel quid chewing in rural Bangladesh: Prevalence, predictors and relationship to blood pressure. Int J Epidemiol 2012; 41: 462-71.

13. Shah N, Sharma PP. Role of chewing and smoking habits in the etiology of oral submucous fibrosis (OSF): a case-control study. J Oral Pathol. Med 1998; 27: 475-9.
14. Muhammad RK, Samia M, Atif M, et al. Chewing of Betel, Areca and Tobacco: Perceptions and Knowledge Regarding their Role in Head and Neck Cancers inman Urban Squatter Settlement in Pakistan. Asian Pac J Cancer Prev 2006; 7: 95-100.

15. Ahmed S. Rahman A, Hull S. Use of betel quid and cigarettes among Bangladeshi patients in an inner-city practice: prevalence and knowledge of health effects. Br J Gen Pract 1997; 47(420): 431-4. 